\title{
REPRESENTACIONES NIHILISTAS DEL PENSAMIENTO DE NAGARJUNA
}

Francisco José JURADO PÉREZ

Universidad de Barcelona

\section{I} ntroducción

El interés de la cultura occidental por el estudio de los rasgos culturales que conforman el concepto de Oriente es un hecho que se puede remontar, cuando menos, a mediados del siglo XII, momento en el que desde las esferas de poder se alentó un acercamiento erudito a los diferentes campos de conocimiento de aquella otra vasta cultura que no era Occidente. Este suceso se sitúa en la convocatoria del concilio de Viena en 1312, en el cual se decretó la creación de cátedras de griego, hebreo y árabe en las universidades para, mediante el conocimiento de estas lenguas y los factores culturales del contexto en el que se empleaban, facilitar la labor evangelizadora de esos territorios y con ello el éxito de las cruzadas. El movimiento estratégico de acercamiento por parte de las estructuras de poder a esa otredad cultural contribuyó a la generación de una serie de clichés que orientaron la labor escrita de eruditos, diplomáticos y comerciantes hacia una visión que colma los textos de tópicos esencialistas ante la imposibilidad de interpretar de una forma local una realidad tan compleja como la ajena.

Aún así, con los cambios en el sistema y en la recepción del pensamiento occidental, desde la irrupción del humanismo y pasando por el Siglo de las Luces hasta el presente, el tipo de acercamiento hacia el pensamiento oriental ha ido fluctuando respecto a ese objetivo inicial promulgado por los poderes, aunque no quiere decir que haya desaparecido. Si todavía en el Renacimiento los nexos de la nociones de «lo oriental» estaban marcados por el poder secular y se basaban en su mayoría en los estudios de las lenguas de las regiones bíblicas (realizados por Erpenio o Guillaume Postel, entre otros), en el siglo XVIII se experimentó cómo los estudiosos de la cultura oriental se fueron desplazando hacia Asia Central, llegando hasta las zonas de influencia de lengua avéstica y sánscrita. Aunque hay que esperar hasta el siglo XIX, con la irradiación cultural y simbólica de París y la labor de Jules Mhol, para que a través de la Societé Asiatique en París se consiga impregnar a los eruditos europeos de la época de lo que se denominaron estudios orientales, la irradiación de los cuales perdura hasta el presente. 
Esta breve reconstrucción basta como marco introductorio para situar el alcance que los estudios orientales han tenido en distintas áreas de conocimiento como la literatura, la filosofía o la política. Pero ¿son los estudios sobre cuestiones que tienen que ver con Oriente una muestra significativa de lo que constituye esa otredad? ¿Es la relación de comprensión que se establece desde Occidente hacia Oriente neutra en nuestros días? O, ¿acaba por construir una imagen distorsionada realizada desde y para Occidente mediante un discurso cultural que pone en circulación una pretendida idea de verdad, en su acepción más metafísica, acerca de qué es aquello que constituye Oriente?

Para tratar de dar respuesta a estos interrogantes se empleará y se incidirá en las analogías y proyecciones nihilistas que se han utilizado sobre su obra para hacer comprensible su pensamiento fuera de su contexto de producción. Por cierto, unas construcciones de sentido sobre su pensamiento que paradójicamente se relacionan con un sistema filosófico, el nihilismo, que pone su centro de atención en la configuración de significados.

A estas cuestiones les están dedicadas las siguientes páginas, en las cuales, para tratar de dar respuesta a estos interrogantes, se tomará como muestra el tratamiento académico que desde Occidente se ha realizado en torno al pensador budista Nagarjuna. La finalidad de analizar estos estudios es incidir en las analogías y proyecciones nihilistas que se han empleado sobre la obra de este pensador para hacer comprensible su pensamiento fuera de su contexto de producción. Así pues, el artículo contextualizará las líneas de pensamiento nihilista más influyentes en la filosofía y examinará el discurso sobre lo oriental desde la perspectiva de Occidente para, de este modo, abordar la caracterización de los rasgos del pensamiento de Nagarjuna y las posibles correspondencias de este con el nihilismo. Para finalizar, se llevará a cabo una deconstrucción de las vinculaciones entre ambos sistemas de pensamiento para volver al estado de la cuestión: la representación del pensamiento occidental sobre aquello denominado como oriental; y que quedará ejemplificado mediante el proceso de «nihilificación» académica que ha sido proyectado sobre las reflexiones de Nagarjuna y su discurso acerca de la vacuidad.

\section{Hacia una construcción del concepto nihilista}

La carga semántica del término «nihilismo» se puede situar entre los siglos XVII y XVIII como consecuencia de los debates filosóficos suscitados por el idealismo alemán, en los cuales se puso de manifiesto la existencia de una relación entre la conceptualización de la singularidad de una realidad y el propio sistema idealista con su interpretación de lo objetivo; tal y como postularon filósofos como F. H. Jacobi, quien «elevó la acusación de nihilismo tanto contra la filosofía teórica como contra la práctica de Kant. En su "mensaje" a Fichte designa el "idealismo" de éste como "nihilismo"» (Weier, 1977: 171). En tanto que el idealismo postula, a grandes rasgos, cómo el mundo real se rige por las imposiciones de la razón, se llega a hacer coincidir lo objetivo con lo subjetivo en el plano intelectual, produciéndose así la duda de la identidad entre sujeto y objeto, esto es, el orden que sostiene e interrelaciona el «yo» con el «no-yo». Con esto, los conocimientos sobre lo esencial y válido se vieron 
cuestionados por la posibilidad de que estuvieran configurados por una suerte de ingeniería filosófica y teorética en cuyos ensamblajes se hallaran propósitos e intenciones coyunturales, los cuales «ya no se podían legitimar y justificar basándose en un sentido existente en sí, suprasubjetivo y extrasubjetivo, pues se encontraron confrontados con una nada objetiva, a la cual se movían ahora» (Weier, 1977: 171). Este proceso supuso una devaluación de los conocimientos racionales junto con el cuestionamiento del modo de funcionar de la razón, de tal forma que en términos de pensamiento filosófico se pone la atención en el grado último al que se pudo llegar con el idealismo: esa posible «nada objetiva». Con estos antecedentes, se puede situar el advenimiento del sistema de pensamiento que incide en la desvalorización de los valores últimos y esenciales a través de una desestabiliazción de los conceptos y que en último grado llega a ese nihil con el que se denomina a esta corriente filosófica, el nihilismo.

Parte de la historia de Occidente en términos de pensamiento se basa en la metafísica del ser, es decir, en la posibilidad de una existencia determinada que transgrede el espacio físico y experimentable del ser humano y que permite explicar el mundo. En este sentido, la filosofía platónica penetró en el sistema de pensamiento occidental a través de su teoría de las ideas y de su estructura de la realidad, la cuales piensan el «ser de las cosas». Esto resulta en su filosofía algo que no está en las cosas mismas porque participan de otra realidad que está fuera, es decir, en las ideas, por lo que es necesario un sistema «para descubrir el modo de ser de las cosas, descubrir lo que hace que las cosas sean, y por eso, al mismo tiempo, descubrir aquello que puede saberse de las cosas; es decir, lo que son» (Marías, 1974: 50). En este punto es en el que entra la metafísica, ya que se produce un problema de carácter epistemológico al no poder descubrir una cosa sin acercarse a la idea, lo que supone que solo se puede conocer al ser y no directamente al ente sobre el cual se proyecta la idea de ser. Aún así, se puede considerar, en estos términos, que Platón también deja entrever la existencia al «no-ser», el cual se constituiría en la imposibilidad del conocimiento directo del objeto, pero su filosofía apuntala al ser en contraposición al no-ser, quedando así instalado para muchos siglos un sistema dualista y jerárquico, los pares de contrarios sobre los que se fundamentan, por ejemplo, las polis y el cristianismo.

De forma muy concisa, se podría afirmar que la metafísica de Platón desvela el ser de las cosas, siguiendo la temprana estela, aunque por otros derroteros, de lo que Parménides denominó el «ente», esto es, las cosas en cuanto que son más allá de los múltiples predicados o propiedades que el objeto pueda presentar; el ente como una esfera sin huecos de no-ser en su propiedad esencial, su «predicado real». A pesar de la problemática filosófica que pudo entrañar la primera configuración metafísica de Parménides y determinados filósofos presocráticos, Platón recoge algunas de estas aportaciones más relevantes y desarrolla un sistema de pensamiento metafísico que se consolida con el paso de los tiempos. Con todo, estos hechos instauran en el debate filosófico las premisas de una dualidad entre «ser»y «no-ser» que impregnan de manera determinante la configuración del pensamiento occidental, y son en gran medida, parte de la crítica del discurso nihilista. 
En atención a la dualidad consolidada a partir de Platón, los sistemas de pensamiento posteriores que han refutado las tesis metafísicas platónicas han contribuido, de manera colateral, a la pervivencia de estas mediante un diálogo que a pesar de enfrentarse, acaba asimilando conceptos del oponente dialéctico. Esto se puede observar en Aristóteles y la aceptación del elemento común entre los objetos, la idea; en San Agustín y el reconocimiento de la idea esencial de «bien», cuya ausencia explica el pecado; en Descartes o Espinoza y el traslado del mundo de las ideas a la parcela de la mente humana, donde el conocimiento de la verdad es un conocimiento ideal; o en Kant y las analogías que se pueden tender entre sus ideas puras y las ideas de Platón. Esta escueta cronología en cuanto a las influencias de la metafísica platónica llega hasta la época contemporánea, pero ya pasada por el filtro de un pensamiento que cuestiona radicalmente sus bases, esto es, el nihilismo, cuyas resonancias llegan hasta el post-estructuralismo o la deconstrucción. Con esta caracterización de lo que no es nihilismo sino más bien idealismo (objeto principal de crítica de este sistema de pensamiento basado en la insustancialidad de esas ideas imperantes) se puede tratar de responder a la cuestión de ¿qué es el nihilismo? Para esta tarea se puede trazar una pequeña cronología que recoja parte del material con el que trabaja este sistema de pensamiento.

De entre los primeros pensadores en los que se puede rastrear cierto carácter nihilista, avant la lettre, están las enseñanzas morales de Pirrón y su influencia sobre la escuela escéptica, la cual supuso una reacción contra los sistemas de pensamiento que alrededor del siglo III a. C. elaboraban supuestos filosóficos con un valor de sentido absoluto aduciendo, entre otros argumentos, que este tipo de acciones no fueran más que opiniones fundadas sobre los conocimientos consensuados en una determinada tradición filosófica. Para este tipo de pensamiento las cosas eran igual de indiscernibles e inconmensurables dado que los conocimientos son alcanzables a través de los sentidos, por lo que al ser sus sensaciones cambiantes, estas tan solo pueden mostrar las apariencias, motivo por el cual estas carecerían de un fundamento último. Este tipo de filosofía aboga por una suspensión de juicios, y con ella, un sistema antimetafísico opuesto a toda construcción de una idea última y absoluta; lo que por otro lado, supondría el fin de la filosofía si se atiende a que la actitud del filósofo es la búsqueda. La disposición de estas enseñanzas recaería sobre el objetivo de llegar a pronunciarse sobre nada y conseguir la ataraxia ${ }^{1}$ o serenidad de espíritu, en sentido moral.

También se pueden encontrar postulados similares a los escépticos en algunos pensadores anteriores como Anaximadro, que alude al principio de las cosas con el término ápeiron (ilimitación) en referencia a un predominio injusto de un contrario sobre otro «que hará volver a las cosas a ese fondo último, sin injusticias, inmortal e incorruptible, donde no predominen unos contrarios sobre los otros» (Marías, 1974: 14); Heráclito, que apunta a la variación o movimiento de las cosas en las que «todo ocurre, todo fluye» dado que la realidad es cambiante y mutable (motivo por el que la palabra «río» no podría designar nunca al mismo «río»); o Demócrito, que apunta a una construcción de imágenes sutiles a través de los sentidos, por lo que la mente no recibiría la realidad en sí misma, sino

\footnotetext{
${ }^{1}$ Dicha suspensión es «ese equilibro de la mente por el que ni rechazamos ni ponemos nada», y dicha quietud es un «bienestar y serenidad de espíritu» (Sexto Empírico, 1993: 55).
} 
una copia, una construcción. A pesar de que estos filósofos presocráticos pudieran apuntar con algunos de sus principios a nociones análogas con las de los escépticos, conservan las resonancias acerca de cuestiones que aluden a una cierta ontología que no acaba de desprenderse de la primera metafísica de Parménides, por lo que no podrían definirse como nihilistas.

No es hasta la llegada de Nietzsche en el siglo XIX que se pueden apreciar parte de las enseñanzas escépticas enmarcadas en un sistema de pensamiento que niega la posibilidad de la metafísica. Con él ya se puede hablar propiamente de filosofía nihilista dado que lleva a cabo una subversión de los valores de pensamiento tradicionales que desestabilizan los postulados dominantes para mostrar cómo se basan en construcciones teóricas que dejan fuera de lugar la propia experiencia sobre la vida. La filosofía de Nietzsche pretende desenmascarar las actitudes y juicios de valor mediante una crítica del lenguaje y de la idea de verdad como consecuencia de la inexactitud entre sujeto y objeto junto con la necesidad humana de una fuerza mediadora entre estos: la fantasía o el relato. De esto modo, los conceptos solo serían construcciones ficcionales útiles para el intercambio comunicativo entre los seres humanos puesto que la naturaleza no trata con conceptos ni géneros, sino con acontecimientos inaccesibles e indefinibles para los cuales creamos aproximaciones por medio del lenguaje; y así se pregunta el filósofo:

¿Qué es entonces la verdad? Un ejército móvil de metáforas, metonimias, antropomorfismos, en resumidas cuentas, una suma de relaciones humanas que han sido realzadas, extrapoladas, adornadas poética y retóricamente y que, después de un prolongado uso se ha olvidado de lo que son, metáforas que se han vuelto gastadas y sin fuerza sensible, monedas que han perdido su troquelado y no son ahora consideradas como monedas, sino como metal (Nietzsche, 1990: 63).

\section{En transición: el discurso occidental sobre Oriente}

Tras el breve esbozo cronológico acerca de la metafísica y el nihilismo, es necesario transitar ahora hacia otro de los conceptos clave en este artículo: las líneas de pensamiento en las que se inserta el pensador budista Nagarjuna, el mahāyāna, una de las principales ramas del budismo. Para llevar esta tarea merecería la pena destacar en este apartado las características que definieran a qué se le puede llamar pensamiento budista para, de este modo, realizar una labor comparatista entre lo denominado «nihilismo» y lo caracterizado como «pensamiento oriental» y así localizar las proyecciones de un sistema sobre otro con la finalidad de establecer una diferenciación radical entre ambos sistemas. Esto no dejaría de ser un método de acercamiento a la cuestión sobre la representación de un cierto nihilismo en el pensamiento oriental mahāyāna en el que elabora su discurso Nagarjuna. Pero antes de desarrollar un análisis similar cabría plantearse si aquello a lo que se denomina «pensamiento oriental» puede considerarse como tal o si, quizá, el objeto de estudio que se pretende como el otro término de la comparación en este artículo deviene en una construcción teórica, al modo de las que denuncia el pensamiento nihilista; hecho que por otro lado no impediría llevar a cabo el objetivo de este análisis.

Reflexionar sobre el pensamiento oriental, en este caso acerca de la parte referida al budismo, desde una óptica educada en la tradición de pensamiento occidental puede llevar al sujeto a configurar una visión del objeto impregnada por el relato que la misma tradición occidental ha proporcionado 
acerca del objeto; cosa que parece inevitable. En este sentido, se suscita la pregunta de «¿cómo se conocen "las cosas que existen" y en qué sentido "las cosas que existen" están constituidas por el que las conoce?» (Said, 1990: 352) así como el cuestionamiento acerca de si el conocimiento se constituye en un conjunto de ficciones ideológicas influenciadas por el relato compartido y consolidado en una comunidad a través de modelos de autoridad. Si esto sucediera de este modo, se podría afirmar que el sentido último de verdad ante el objeto de estudio no sería intrínseco a este, sino que devendría del resultado de todo un proceso de institucionalización basado en la repetición de un discurso grupal y cuya exactitud puede estar cimentada argumentalmente sobre la fuerza mediadora tanto de la fantasía como de la rigurosidad.

El discurso sobre el pensamiento oriental podría tratarse, de este modo, como «una serie de discursos apoyados en unas instituciones, en un vocabulario, en enseñanzas, en imágenes, en doctrinas e incluso en burocracias y estilos coloniales» (Figueroa, 2004: 102) que legitiman una visión determinada de Oriente desde una óptica occidental. Esta configuración se basaría en la repetición y reformulación de proposiciones nuevas acerca de aquello denominado como «pensamiento oriental» a través de un proceso de institucionalización formado tanto por la literatura «literaria», política o científica, para poseer así una fuente de autoridad aceptada que avale las tesis. Este hecho no conlleva que no se pueda consensuar una definición esencial para referirse a aquello «otro» en oposición a esto «otro», en términos de pensamiento, pero sí presenta cierta problematización si se atiende al fundamento bajo el cual se diseñan los parámetros con los que se articulan las imágenes que se asocian a Oriente desde las instituciones de Occidente.

En este punto se pueden retomar algunas de las citas de Nietszche referentes a las verdades producidas por un lenguaje metafórico con el que se elaboran conceptos consensuados socialmente y que son útiles para construir ideas válidas acerca de determinados objetos o fenómenos. Esto mismo puede suceder con la representación del pensamiento oriental mahāyāna que se presenta en este artículo y que sí está académicamente avalado y en circulación. Pero a pesar de la consciencia sobre este se ha de incidir en que el «uso genealógico del lenguaje presupone, entonces, que el lenguaje es capaz de producir verdades que se naturalizan al olvidar su propia génesis artificial» (Figueroa, 2004: 103), motivo por el cual se pueden desprender en las siguientes líneas estructuras en forma de paradoja que transiten entre el planteamiento de una tesis basada en el análisis y su propio cuestionamiento como argumentación en forma de verdad última o absoluta.

Quizá la cita a retomar pudiera ser esta:

Sólo mediante el olvido de ese mundo primitivo de metáforas, sólo mediante el endurecimiento y la petrificación de un fogoso torrente primordial compuesto por una masa de imágenes que surgen de la capacidad originaria de la fantasía humana, [para] reconocer ante sí mismo que el insecto o el pájaro perciben otro mundo completamente diferente al del hombre y que la cuestión de cuál de las dos percepciones del mundo es la correcta carece totalmente de sentido, puesto que para decidir sobre ello tendríamos que medir con la medida de la percepción correcta, esto es, con una medida de la que no se dispone (Nietzsche, 1990: 72). 


\section{Hacia un esbozo del pensamiento de Nagarjuna}

El sistema de pensamiento de Nagarjuna, inserto en la rama mahāyāna del budismo, se presenta textualmente como un corpus de enseñanzas de carácter contradictorio, e incluso paradójico, bajo un estilo sobrio cercano al aforismo y con cierta retórica que puede lindar con el discurso poético. Nacido alrededor del siglo III de la era cristiana, se le considera fundador de la escuela madhyamaka, denominada también como la escuela de la vía media, la cual se puede caracterizar en términos filosóficos por la elaboración de argumentos que mediante la reducción al absurdo muestran que las aserciones (con las que se pretende afirmar un estado de cosas que ocurren en el mundo como verdaderas) carecen de un fundamento sólido que las puedan constituir como verdades últimas. Este tipo de refutación estaría relacionada con una visión mediante la cual se pueden considerar las explicaciones de los fenómenos como un conjunto de convenciones cuya aceptación deviene de un consenso coyuntural en un tiempo y lugar. Así, se apuntaría a que la expresión de los fenómenos es el producto de las articulaciones de la mente respecto a todo aquello que la circunda, hecho por el que estos estarían vacíos de una esencia concreta, del mismo modo que la mente carecería de unas estructuras eternas e inmutables con las que generar dichas esencias fenoménicas.

La idea de vacuidad tiene una especial relevancia, ya no solo en las enseñanzas budistas, sino en otros sistemas de pensamiento orientales como el taoísta, y su referente remite en el budismo a la inviabilidad de una satisfacción permanente a través de la apropiación de un objeto por parte de un yo movido por el deseo, el cual a su vez remite a la noción de ilusión y transitoriedad. En este punto es donde se produce un choque entre los extremos de la permanencia y la transitoriedad y cuya vía media, reside precisamente, en la vacuidad de ambos límites. La concepción del vacío distingue a grandes rasgos, por un lado, el hīnayāna, referente a la noción de vacío sobre la persona, esto es sobre el «yo» incapacitado por su limitación finita para indicar un elemento permanente más allá de sus manifestaciones, configuradas por los dharmas transitorios; y por otro lado, el mahāyāna, que alude a la idea de vacío ya no aplicada a la persona, sino a todos los fenómenos. Con esta diferenciación respecto al término del «vacío» en el budismo, se puede establecer que mientras el hīnayāna revela las cosas en analogía a un cuerpo vacío y carente de esencia, el mahāyāna expone la posibilidad de que ni siquiera dichos cuerpos, carentes de sustancialidad, puedan llegar a ser; de lo que se desprendería la carencia de un fundamento último y verdadero sobre el cual pudiera reposar todo lo existente.

El rechazo a un tipo de verdad última se puede explicar mediante, precisamente, un concepto: la interdependencia. Si toda forma es vacía dada su formulación respecto a unos fenómenos condicionados por la percepción, también el fondo de esas formas resultaría vacío en términos silogísticos: se trataría de un contenido vacío debido a su impermanencia. Los fenómenos aislables por los mecanismos de lógica carecerían de una consistencia sólida porque en su misma formulación surge una escisión arbitraria en base a unos supuestos colectivos entre el objeto y el mundo circundante para aislarlo y expresarlo sin todo aquello que lo rodea y que además, deviene con él en su mismo ser y estar ahí, por lo que una parte de ese objeto quedaría escindida. De este modo, las cosas estarían vacías porque emergen de una forma condicionada, porque hay una relación de interdependencia entre ellas 
de tal suerte que no se podría hablar de múltiples cosas, sino más bien de una cosa en su multiplicidad. Si se pudiera hablar de una verdad última en los términos del pensamiento mahdhyamaka, se podría decir que esta sería la sûnyata, el término «vacío», que significa: «que ninguna forma de multiplicidad, ninguna formulación conceptual o verbal, se adecua a la "realidad" así denominada. La sûnyata es el presupuesto necesario tanto para la aparición como para la desaparición de los entes y la condición de posibilidad para liberarse del samsâra (el ciclo del renacimiento)» (Gómez, 2008: 873).

La interdependencia es un término que hace referencia a que las cosas se apoyan mutuamente entre sí, lo que rodea al objeto descansa sobre este a la vez que este reposa sobre todo lo demás, por lo que nada puede existir de manera aislada a consecuencia de su relación condicionada con el contexto, lo que deriva en que ningún fenómeno puede existir por naturaleza propia y en que su expresión remite a una forma y fondo vacía, únicamente reconocible por la convención institucionalizada. En este sentido, aquello denominado como realidad haría referencia a un proceso complejo en que nada existe de forma independiente y en el que si nada tiene independencia de lo demás, los términos del lenguaje para designar los fenómenos aislados se convertirían en las tentativas de la mente por situarse ante algo inaprensible «¿Cómo percibir un ente real entre las cosas que cambian? Viéndolo en términos de naturaleza propia. Pero al hacer esto percibes las cosas que devienen como sin causas ni condiciones, y contradices, por tanto, las nociones de causa material, agente» (Nagarjuna, 2004: 179). La idea de interdependencia conlleva que la naturaleza propia de las cosas, sus rasgos esenciales, no son más que límites para el conocimiento ya que el objeto al depender de sus antecedentes ya estaba, en cierto grado, en ellos al ser estos causa de su procedencia; con esto, no se podría establecer una diferenciación radical entre ellos, y por ende, no se podría trazar un límite que los separara de manera radical para afirmar que no fueran lo mismo, aunque de distinto modo.

La condicionalidad de las cosas supondría que ningún fenómeno puede constituirse como una entidad separada y divisible de todo lo que lo rodea, de modo que se produciría, en términos de pensamiento, una regresión infinita al tratar de asir el objeto, el cual por la relativización de las relaciones causales perdería su fundamento y así se acercaría a cierta vacuidad. Aún así, la vacuidad entendida a través de los textos de Nagarjuna no puede hacer referencia a la «nada» o a cualquier absoluto abstracto producido mediante el lenguaje porque esa vacuidad no pretende ser un principio trascendente más allá de los fenómenos, sino más bien un carácter intrínseco a estos, «pues no es concebible fenómeno que no sea relacional, que no tenga un origen condicionado: por esta razón no podemos hacernos a la idea de un $\operatorname{dharma}^{2}$ que no sea vacío» (Nagarjuna, 2004: 181). Si se atendiese a la vacuidad en sentido absoluto se estarían sustituyendo, por otra estética, las enseñanzas de Nagarjuna, ya que estas no encierran una verdad última e indiscutible a pesar de que sus argumentos se dirijan hacia un postulado lógico determinado con cierta presunción de irrefutabilidad. Es en este punto en el que se pueden encontrar las paradojas de la vía media (como se conocen también sus enseñanzas) puesto que, por un lado, habría que atender a la relevancia del término «vacuidad» y la

\footnotetext{
${ }^{2}$ Este término alude semánticamente a conceptos como «ley natural», «religión», «sustento», etc. lo que remite a una cierta idea de orden.
} 
complejidad argumental que conlleva, pero al mismo tiempo, por otro, habría que percatarse de que este mismo término no es más que una palabra con un significado convencional y no trascendental: «El núcleo de la doctrina es el vacío, incluso la idea de vacío» (Maillard, 2000: 53).

Del mismo modo que los objetos, las palabras y las aserciones se originan en la interdependencia, la cual las haría carentes de una naturaleza propia, esto es, vacías, también la propia vacuidad acabaría careciendo de sustancialidad. Gran parte del discurso filosófico de Nagarjuna desemboca en la conclusión de que no hay diferencia alguna entre samsāra y el nirvana, y aun con esta aserción tan totalizadora, él mismo, a su vez, remite a la posibilidad de que dada la vacuidad de todas las doctrinas, todas las conjeturas acerca de la permanencia también estarían vacías; por ello lleva a cabo el abandono de todas las conjeturas y de la discusión, porque como cualquier afirmación, en este sentido, es una afirmación engañosa. Con esto se transmite que ninguna afirmación tiene realidad en sí misma por estar sujeta a causas y condiciones o - como se diría hoy - por estar inscrita en una red de textos (intertextualidad) a los que hace referencia y de los que es un efecto. «Incluso la doctrina de la vacuidad tiene la naturaleza de la ilusión (deconstruyéndose a sí misma) y por ello se considera parte del maya ${ }^{3}$ » (Arnau, 2005: 10). En este sentido, Nagarjuna se autocuestiona, ya que el sentido de sus enseñanzas podría ser también ilusorio.

A modo de síntesis sobre este apartado, se podría decir que la propuesta de Nagarjuna hace referencia a un aposicionamiento filosófico en el que no es posible ni afirmar ni refutar ninguna tesis, a la vez que lleva a cabo una deconstrucción final de sus afirmaciones y negaciones:

La dialéctica de Nāgārjuna aspira así a proporcionar cierto valor terapéutico, su crítica del lenguaje (y su poder para crear esencias) se resuelve en un modo de ver el mundo, el lenguaje y el pensamiento que haga posible la experiencia del despertar. Si las cosas tuvieran naturaleza propia, el mundo se encontraría petrificado y no sería posible la transformación espiritual que lleva al logro de la liberación (Arnau, 2006: 15).

\section{Entre correspondencias y discordancias: proyecciones nihilistas en el pensamiento de Nagarjuna}

En este punto del artículo y una vez caracterizadas, a lo sumo, las nociones de lo que se puede denominar como pensamiento nihilista y de los preceptos que ayudan a ilustrar el pensamiento de Nagarjuna, conviene establecer el objeto último de este artículo: analizar las proyecciones que se pueden establecer entre el nihilismo y las enseñanzas del pensador oriental para, precisamente, establecer estas proyecciones como tales, es decir, cómo la construcción de conexiones intertextuales sujetas a unas convenciones permiten la comprensión de un sistema de pensamiento en comparación con otro.

Si hubiera que caracterizar la tradición filosófica occidental en su conjunto, a grandes rasgos, se podría afirmar que buena parte de su pensamiento descansa sobre la premisa de que el mundo está compuesto de sustancias que pueden tener una existencia separada de las demás, de tal modo que se ha podido llegar a la elaboración de teorías metafísicas que apunten a tales existencias más allá de lo

\footnotetext{
${ }^{3}$ Esta palabra hace referencia a la concepción de una imagen ilusoria del mundo fenoménico causada por los sentidos.
} 
tangible bajo férreos sistemas argumentativos. Aun así, la filosofía occidental también ha argumentado matices a la sustancialidad mediante autores como Descartes o Kant y críticas radicales como las de Nietzsche, y es con este filósofo y su concepción acerca del nihilismo con las que se ha relacionado en términos comparativos el pensamiento de Nagarjuna:

[...] a fines del siglo XIX en Europa, Nāgārjuna fue considerado un nihilista; a mediados del siglo XX, bajo la influencia de la filosofía analítica, un lógico y un escéptico. Y más recientemente, el posestructuralismo y la deconstrucción han orquestado nuevas interpretaciones sobre Nāgārjuna, en sintonía con sus propios supuestos (Arnau, 2005: 498).

En este sentido, al igual que se puede establecer el término de comparación con Nietzsche, si se atiende a la interdependencia aplicada a este artículo, también se pueden establecer analogías con los términos de pensamiento con los que se puede relacionar a la filosofía nietzschiana, esto es, entre otras corrientes de pensamiento, el escepticismo pirrónico.

Uno de los primeros parangones avant la lettre que se pueden encontrar en la filosofía occidental en relación al nihilismo y a las enseñanzas de Nagarjuna son las ideas que Sexto Empírico plasma acerca de la filosofía de Pirrón en sus Esbozos pirrónicos. Entre ambas corrientes se puede establecer una vinculación si se atiende a que en los esbozos se habla de una intención en la que «el criterio de la orientación escéptica es el fenómeno, llamando implícitamente así a la representación mental» (Sexto Empírico, 1993: 60), la cual se presenta como cierta habilidad dogmática de la razón con el fin de obtener una verdad mediante mecanismos metodológicos. Esto puede recordar a que «como consecuencia de ver el cambio en las cosas, uno acierta a entender que carecen de esencia. Puesto que no hay ninguna entidad con naturaleza propia, se dice que las cosas son vacías» (Nagarjuna, 2004: 117); lo representado no estaría contenido en su representación. En este sentido, se pueden establecer vínculos entre la noción de representación que apuntan los esbozos pirrónicos y el contenido vacío que estas representaciones conllevan para Nagarjuna, ya que para ambos sistemas no existe una correlación sustancial entre el término representativo y aquello representado porque son una construcción mental. Con esto, la noción de «vacuidad» podría yuxtaponerse a la noción escéptica del epojé (suspensión), dado que al apuntar ambos pensamientos a la representación de aquello entendido como verdad última se acepta el vacío de cualquier aserción, y por lo tanto, la suspensión de su sentido semántico.

Ambos pensadores pueden relacionarse con preceptos nihilistas atendiendo a que apuntan a una carencia de contenido en aquello que se podría considerar como sustancial y pleno de sentido mediante los silogismos de la razón. La superación de las doctrinas dualistas acaba por ser una de las máximas a alcanzar en los textos de la vía media, fuera de los pares excluyentes de los extremos, y en el escepticismo, la suspensión de todo juicio para llegar a la ataraxia. Así, se puede observar cómo, por un lado, en los Fundamentos de la vía media, Nagarjuna expone que «el que adopta el concepto de entidad existente se ve obligado a escoger entre lo eterno y la nada, puesto que asume lo permanente y lo impermanente» (Nagarjuna, 2004: 115), mientras que por otro, en los Esbozos pirrónicos se manifiesta que «no es nuestro propósito [...] dar a entender que el criterio de Verdad sea inexistente [...]; sin asegurar que sean ni verdaderas ni más probables que las contrarias, sino concluyendo en la 
suspensión del juicio por la aparente equivalencia de esas razones» (Sexto Empírico, 1993: 162-163). Mediante estos ejemplos, ambas filosofías pueden corresponderse en la pretensión de situarse fuera de las dicotomías excluyentes del entendimiento para acceder a aquello otro más allá, incluso más allá de lo que ese «aquello más allá» pueda representar mediante el lenguaje. Ante ello, ambos autores optan por un silencio similar.

En determinados puntos de los discursos de ambos pensadores pueden encontrarse conceptos paralelos, como los mencionados, al desarrollar funciones estructurales similares en la elaboración de sus postulados, hecho que por otro lado también se puede relacionar con la hipótesis de una fluctuación entre el pensamiento griego y el hindú en los primeros siglos de esta era, dado que «en la época del escepticismo pirrónico reyes griegos dominaban el noroeste de la India y conocían la filosofía de Atenas» (Gómez, 2004: 881). Aun así, no se podría hablar propiamente de un nihilismo en ambos pensadores ya que el silencio por el que acaban optando les puede alejar de las doctrinas nihilistas en tanto el aposicionamiento que denotan. Del mismo modo, tampoco podría considerarse el pensamiento de los Esbozos pirrónicos como medialista, ni las enseñanzas de Nagarjuna como escépticas porque sus silencios no son el mismo, aunque puedan establecerse puntos en común. Por un lado, Sexto Empírico esboza el escepticismo como una aptitud retórica con la que oponer fenómenos a juicios mediante argumentos de igual fuerza (isostheneia) y de este modo llegar a una suspensión filosófica que conduzca a la ataraxia, mientras que por el otro lado Nagarjuna no podría ser considerado un escéptico porque el alcance de ese silencio no sería mediante la fuerza igualadora de argumentos en una pugna dialéctica en pro de una suspensión, sino más bien, a través de la desintegración de los elementos del propio sistema de su discurso.

De regreso al pensamiento propiamente nihilista y tomando como punto de referencia la filosofía de Nietzsche, también se pueden establecer con estos postulados filosóficos las doctrinas ya señaladas en torno a Nagarjuna. Una de las convergencias que se podrían indicar con más proximidad sería que en ambos sistemas hay una dialéctica que aboga por el rechazo absoluto de la idea dogmática con pretensión de verdad última. Esto lo apunta Nietzsche cuando afirma que el hombre «parte del error de creer que tiene estas cosas ante sí de manera inmediata como objetos puros. Olvida, por lo tanto, que las metáforas intuitivas originales no son más que metáforas y las toma por las cosas mismas» (Nietzsche, 1990: 68), lo que se puede entroncar con algunos de los versos de Nagarjuna en los Fundamentos de la vía media cuando escribe que «en ningún lugar descubriremos jamás una entidad que podamos considerar como surgida a partir de sí misma [...] ningún ente tiene su naturaleza propia o consustancial en el conjunto de las condiciones que supuestamente lo producen» (Nagarjuna, 2004: 55). Con estas citas se pueden observar los vínculos entre ambos sistemas en relación a la negación del todo absoluto metafísico a través del cual, y mediante el intelecto, tratar de asir en conceptos y relatos todo aquello que rodea al propio acto de habla en torno a un fenómeno.

A pesar de todo lo apuntado, no se podría calificar propiamente de un nihilismo metafísico al pensamiento de Nagarjuna dado que sus doctrinas no giran alrededor del no-ser, aunque sus postulados estén cerca de los enunciados, por un lado, del escepticismo, y por otro, de los nihilistas. Los 
Fundamentos de la vía media se alejan de la construcción de un absoluto en torno las ideas de vacuidad e interdependencia porque estas mismas son incluso refutadas al final de la argumentación, por lo que esta vía se sitúa fuera de la polaridad con la que el nihilismo trata de apuntar a un rechazo absoluto de la idea de ser. Aun así, el propio sistema medialista también remite a un absoluto cuando hace referencia a un determinado abandono de toda conjetura para conseguir una libertad de acción no polarizada entre el ser y el no-ser. Si ambos sistemas de pensamiento coinciden en la idea de que el vacío no es, como en la tradición filosófica occidental, una sustancia yuxtapuesta a los seres concretos sino más bien una propiedad del reverso de la propia co-sustancialidad intrínseca de los objetos, se podría afirmar que el no-ser es el vacío, pero entonces, ¿no devendría este no-ser en un ser? Más allá de la respuesta, Nagarjuna parece apuntar hacia otra parte, lejos de cualquier dualismo, con su Abandono de la discusión: «Nagarjuna nos recuerda que "el Bienaventurado (el Buda histórico Gautama) refutó tanto el ser como el no-ser: rechazó ambos”. Esta negación de la naturaleza propia es una forma de evitar la cosificación del pensamiento, su paralización en hipóstasis sustancializadas» (Gómez, 2004: 886).

Las tesis del pensador budista parecen situarse un paso más allá del rechazo del ser relacionado con los postulados esbozados desde Parménides hasta Platón y situados en la elaboración de una teoría del saber acerca del ente. Pero Nagarjuna también parece situarse más allá de las tesis que niegan la posibilidad de un ser mediante la suspensión argumentativa o el rechazo de un relato convencional que trata de evitar que el hombre se enfrente a aquello que puede haber tras el velo del intelecto, esto es, nada. Con los textos de Nagarjuna, el lector se aproxima hacia una especie de diálogo paradójico entre los términos del ser y del no-ser que acaba por autoconsumirse mediante la degradación misma de las tesis que apuntan hacia un no ser entendido en términos occidentales; una degradación que acaba por restar en un silencio que ya no puede decir el qué acerca de la discusión. En este sentido, interpretar este silencio como una posición hacia el vacío de las palabras, hacia un nihilismo en sentido pleno, sería una construcción conceptual dualista de difícil encaje en la vía media «Si hubiera algo no vacío, entonces habría algo llamado vacío. Sin embargo y puesto que no hay nada que sea no vacío, ¿cómo podría haber algo vacío?» (Nagarjuna, 2004: 117).

A modo de conclusión, las proyecciones analógicas en torno a ciertas resonancias nihilistas en el pensamiento de Nagarjuna no dejan de ser válidas siempre y cuando se tengan en cuenta como construcciones conceptuales mediante las que situar al pensador oriental en una estela de discurso aproximada a sus doctrinas y en beneficio de una comprensión primera de sus postulados; comprensión que si se atiende precisamente a los conceptos comunes entre nihilismo y medialismo, puede que también fuera la última, dados los mecanismos conceptuales que impregnan al objeto de estudio para no desvelar, quizá, la imposibilidad de comprensión última de las doctrinas de Nagarjuna. Las paradojas de sus textos muestran esta posibilidad, además de todas aquellas que se puedan elaborar mediante otros argumentos, y precisamente, los que aparecen en este artículo, no dejan de participar de esta práctica en un modo académico, pretendiendo establecer, en este caso, argumentos sobre las posibles analogías entre el pensamiento nihilista y las enseñanzas de Nagarjuna como construcciones 
conceptuales para intercambios de conocimiento. Pero sin pretensión absoluta, porque quizá, como el pensador apunta: «todo es verdad y nada es verdad. Y todo es verdad y no verdad. Esta es la enseñanza de los Budas. Sin depender de otra, serena, no fabricada por la elucubración, más allá de toda discriminación, sin distinciones: tales son las características de la realidad» (Nagarjuna, 2004: 145).

\section{Bibliografía}

ArnaU, J. (2005): «Genealogía de la vacuidad», Estudios de Asia y África, 40/3, pp. 495-518, en http://www.redalyc.org/articulo.oa?id=58640301 (última consulta, 22-4-2016).

- (2006): «Introducción», en NAGARJUNA (2006), pp. 9-24.

FigueroA, J. A. (2004): «Edward Said, la periferia y el humanismo o tácticas para trascender el postmodernismo», Iconos, 18, pp. 100-108, en http://www.flacso.org.ec/docs/figueroa18.pdf (última consulta, 22-4-2016).

GómeZ, A. (2008): «Nagarjuna y la dialéctica del origen condicionado», Pensamiento, 64/242, pp. 865-887.

MAILlARD, C. (2000): La sabiduría como estética. China: confucianismo, taosímo y budismo. Madrid, Akal.

MARÍAS, J. (1974): Historia de la filosofía. Madrid, Revista de Occidente.

NAGARJunA (2004): Fundamentos de la vía media. Ed. y trad. J. Arnau. Madrid, Siruela. (2006): Abandono de la discusión. Ed. y trad. J. Arnau. Madrid, Siruela.

NiETZSCHE, F. (1990): Sobre verdad y mentira en sentido extramoral. Trad. L. M. Valdés y T. Orduña. Madrid, Tecnos.

SAID, E. (1990): Orientalismo. Trad. M. L. Fuentes. Madrid, Libertarias.

SEXTO EMPÍRICO (1993): Esbozos pirrónicos. Ed. y trad. A. Gallego y T. Muñoz. Madrid, Gredos.

WEIER, W. (1977): «Orígenes del nihilismo en el idealismo alemán», Anuario Filosófico, 10/2, pp. 171-190, en http://dadun.unav.edu/bitstream/10171/1930/1/08.\%20WINFRIED\%20WEIER\% 20\%28W\%C3\%BCrzburg\%29,\%200r\%C3\%ADgenes\%20del\%20nihilismo\%20en\%20el\%20i dealismo\%20alem\%C3\%A1n.pdf (última consulta, 22-4-2016). 